\title{
EFFECTS OF MACROECONOMIC CONDITIONS ON THE INCIDENCE OF MOTOR VEHICLE ACCIDENTS
}

\author{
AleXANDER C. WAgenaAR \\ The University of Michigan, Transportation Rescarch Institutc, Ann Arbor, MI 48109, U.S.A.
}

(Received 27 September 1983)

\begin{abstract}
The economic recession has been suggested as a probable cause of the significant decline in traffic casualties in the U.S. in the early 1980 s. The present study was designed to identify the underlying relationship between changes in economic conditions, as reflected in the rate of unemployment, and motor vehicle crash involvement. The potentially intervening influence of vehicle miles traveled was also examined. ARIMA and dynamic regression time-series modeling procedures were used to assess the direction, magnitude, and lag structure of the relationships. Results revealed a significant concurrent inversc relationship between the rate of unemployment and the frequency of crash involvement, and a significant lag 1 positive relationship between these two variables. Vehicle miles traveled was not a significant intervening influence between unemployment and crash involvement. Summing the concurrent and lagged effects indicated a net negative relationship between unemployment and crash involvement. However, the magnitude of the effect is quite small, accounting for only a small portion of the total decline in traffic casualties in recent years.
\end{abstract}

Injury and death caused by motor vehicle crashes have recently received increased attention in the U.S. New policies and programs designed to reduce traffic casualties have proliferated. Some 40 states now require that young children be adequately restrained when travcling in a motor vehicle [Physicians for Automotive Safety, 1983; Highway and Vehicle Safety Report, 1983]. Higher legal drinking ages have been implemented in 30 states, primarily as a means to reduce alcohol-related crashes among youth [Wagenaar, 1983]. Other laws focused on alcohol-impaired drivers of all ages have been strengthened. In addition to such high-profile changes in public interest and traffic safety laws, most states and localities continue with a wide variety of law enforcement, educational, and public health efforts designed to reduce trauma due to traffic crashes. Corresponding to the heightened interest in highway safety, the death and injury toll due to traffic accidents has declined. The number of traffic fatalities in the U.S. compared with the previous year declined $3.5 \%$ in 1981 , and $10.8 \%$ in 1982 [Cerrelli, 1983]. Given that such significant dcclines in casualties occurred at the same time as strengthened countermeasure cfforts, one might conclude that recently implemented policies and programs are successfully reducing the frequency and severity of traffic accidents. Numerous confounding factors make such a conclusion premature. Even when controlled scientific evaluations of specific countermeasure programs are available, there remain other variables that must be taken into account. One such potentially confounding factor is the influence of macroeconomic conditions on the rate of crash involvement. It was the goal of this study to identify whether general economic conditions significantly influence crash rates, and to measure the effects so that they might be taken into account when assessing the success or failure of current prevention efforts.

Findings concerning the effects of macroeconomic conditions on crash rates should be of immediate interest to policy makers and program managers attempting to reduce the incidence of traffic accidents. If the severe recession of the early $1980 \mathrm{~s}$ is followed by a period of significant economic expansion, as many analysts predict, effects of the changing economic circumstances may overwhelm expected policy or program effects. For example, the limited evidence to date indicates that significant reductions in motor vehicle crash rates in recent years may be due to the economic recession. If local, state, and national agencies implement and evaluate programs to reduce crash involvement during a time of economic expansion, inaccurate conclusions may be made that the intensified prevention efforts had no beneficial effect. Without detailed information on the nature of the 
potentially confounding effects of economic conditions, new policies and programs currently being implemented may not contribute to a major improvement in the state of knowledge concerning effective means for prevention of traffic casualties.

\section{BACKGROUND}

Interest in the influence of economic conditions on behavior is not new. Several social scientists over the past century have noted the link between economic conditions and social behavior [Durkheim, 1951, originally published in 1897; Burgess, 1925; Ogburn, 1936; Cottrell, 1951]. Sociologists, noting that upward social mobility is defined as normative in American society, have pointed out that lack of such mobility therefore significantly disrupts a person's definition of self and pattern of interpersonal relationships, and reduces one's integration into the social system [Mizruchi, 1964].

One consequence of economic recessions that has been studied in some detail is psychological stress and associated mental illness. Dohrenwend [1975] and Liem and Liem [1978] reviewed numerous cross-sectional studies, and pointed out that most have found an inverse relationship between socioeconomic status and mental illness. More convincing of a causal relationship between undesirable economic change and mental illness are longitudinal or time-series studies. Fifteen aggregate time-series studies of the effect of economic change on mental health were reviewed by Dooley and Catalano [1980], Catalano and Dooley [1981]. Although specific findings on the nature of the observed effects vary, all 15 studies found significant relationships between economic change and mental disorder (as reflected in suicide rates, admissions to mental hospitals, and self-reported mood). Kasl and Cobb [1979] monitored individual workers prior to, during, and after plant closings, and found significant changes in reported symptoms of disorder.

Several studies have examined the relationship of economic conditions to the incidence of a variety of health problems other than mental stress, such as cardiovascular diseases and infant mortality [Catalano and Dooley, 1983]. The most frequent finding is that negative changes in economic conditions, such as increased unemployment rates, are associated with increased incidence of health problems.

A contrary view was expressed by Eyer [1977], who noted that death rates for accidents, heart discase, stroke, liver cirrhosis, influenza, and other causes (with the exception of suicide and homicide) rise during periods of business expansion, and fall during recessions. Eyer acknowledged that suicide and homicide death rates as well as mental illness indicators rise during recessions, rather than during periods of economic growth. However, since suicide and homicide represent only about $2 \%$ of the total death rate, Eyer concludes that cconomic prosperity is the more serious public health problem, rather than economic recession.

The broad literature on health effects of economic change includes very little discussion of the effects of the economy on injuries, the leading cause of death for those age 1 to 44 [National Safety Council, 1982]. Some researchers, like Catalano and Dooley [1983], measurc the dependent variable by asking respondents whether they have been ill or injured in the past three months. Because responses were coded dichotomously (ill or injured: yes/no), no separate information concerning the effect of economic change on injury rates was obtained. The relationship between economic conditions and motor vehicle accidents, the leading cause of trauma-induced death, has been given even less research attention. One exception is a very brief report by the Insurance Institute for Highway Safety [1983]. Plots of changes in traffic deaths and changes in the Industrial Production Index from 1976 through 1982 showed similar patterns. Although no statistical analyses were reported, the apparent correlation is used as the basis for the conclusion that the economy "accounted for the 1981-82 downturn in deaths".

In summary, a diverse body of literature indicates that economic conditions influence a number of health problems. The findings, however, vary from study to study, and there is a dearth of research focused on the effect of economic conditions on injury rates. The present study was designed to clarify the effects of economic conditions on motor vehicle crashes and resulting injury and death rates. 


\section{HYPOTHESES}

The specific measure of economic conditions used in the current study is the rate of unemployment. Two types of effects of the unemployment rate on crash involvement were hypothesized. First, that high rates of unemployment would lead to less motor vehicle travel, which would in turn cause a reduction in frequency of traffic crashes. Economic uncertainty and reduced disposable income associated with high unemployment rates may cause a reduction in discretionary driving. Reduced exposure to the risk of involvement in traffic crashes is likely to reduce the aggregate number of crashes.

The second hypothesized effect of unemployment on crash involvement is not mediated by vehicle miles traveled. The argument is as follows. High rates of unemployment lead to higher levels of mental stress in the population. Increased stress associated with job loss or feared job loss during a recession might cause more aggressive driving patterns (i.e. higher threshold of acceptable risk). A consequence may be increased crash rates, in spite of no change in amount of automobile travel. Note that increased stress associated with high unemployment is not limited to specific individuals who lose their jobs. Awareness among the entire population of an increased rate of unemployment may increase their level of apprehension and stress experienced, even though they themselves are not subject to job loss. Because high levels of stress are known to be associated with increased risk of involvement in traffic accidents [Appel and others, 1980; Selzer and Vinokur, 1975; Holt, 1982], an increase in rate of unemployment may result in an increase in automobile accidents.

These two hypotheses represent opposite effects of a change in unemployment on crash involvement. This study was not only designed to identify which of these hypotheses is supported by the data, but also to assess the nature of the lag structure of observed effects. The effect of changes in unemployment rate may not be limited to a single immediate direct or inverse effect, but may be dynamic, evolving over the months following a change in unemployment. Both effects may be present, but have different lag structures. The current study assessed both simultaneous and dynamic relationships (with lags from 1 to 9 months) between unemployment rate, vehicle miles traveled, and crash involvement.

\section{METHODS}

The analysis methods developed by Box and Jenkins [1976] were used to construct dynamic time series models of the relationships under study. All variables were measured on a monthly basis from January 1972 through December 1982 . The dependent variable was the number of drivers involved in motor vehicle accidents in Michigan in which there was at least one injury (Fig. 1). These data were based on detailed investigative reports for all traffic accidents that were reported to police during this period. The goal of the study was to identify effects of economic conditions on typical drivers; therefore, to avoid the potentially confounding influence of economic conditions on traffic directly related to commerce (heavy truck traffic, for example), only passenger cars, light trucks, and motorcycles were included in the crash involvement indicator.

The independent variable, economic conditions, was operationalized using the percent of Michigan civilian labor force that is unemployed (i.e. not currently employed and actively seeking employment). These data, based on a household sample, can be found in Verway [1983]. Michigan was selected as the jurisdiction for study not only because of the availability of comprehensive data on crash involvement, but also because the state has experienced wide variation in the rate of unemployment over the past decade (Fig. 2). High variance in the independent variable facilitates the identification of its effects on the dependent variable.

Finally, a measure of motor vehicle miles traveled was incorporated into the study, to assess its potentially intervening effect between unemployment and crash involvement. Vehicle miles traveled is estimated on a monthly basis by the Michigan Department of Transportation, based on both traffic counter and motor fuel sales data. While estimation of vehicle miles traveled is an inexact science, these data represent the best currently available measure of exposure to the risk of crash-related injury (Fig. 3). 


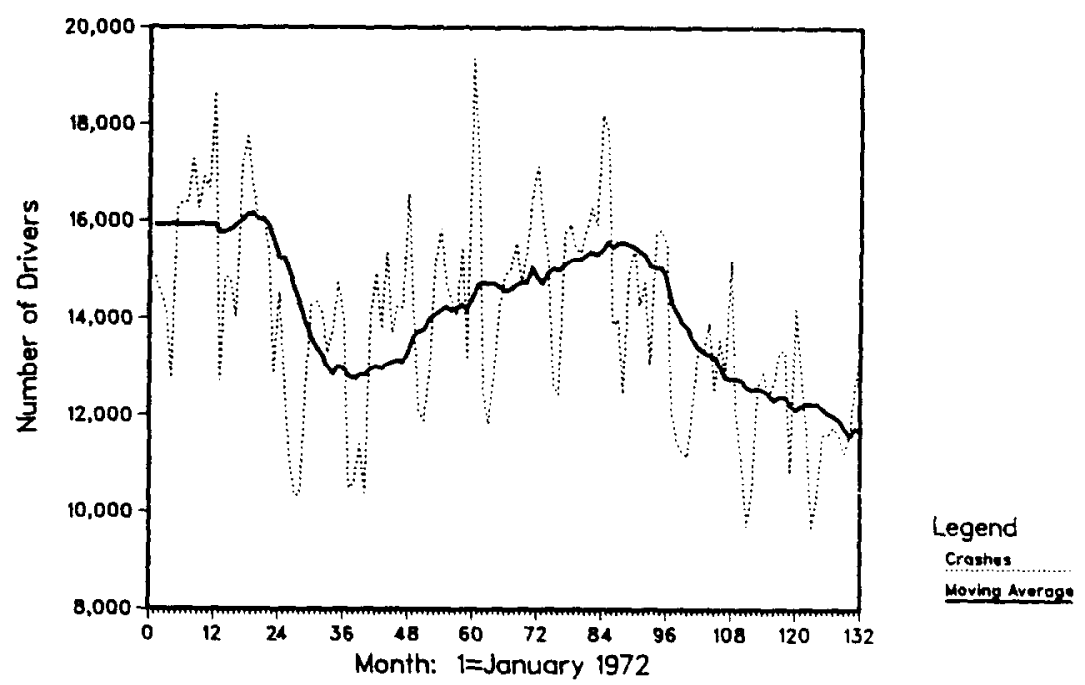

Fig. 1. Michigan drivers involved in injury motor vehicle crashes.

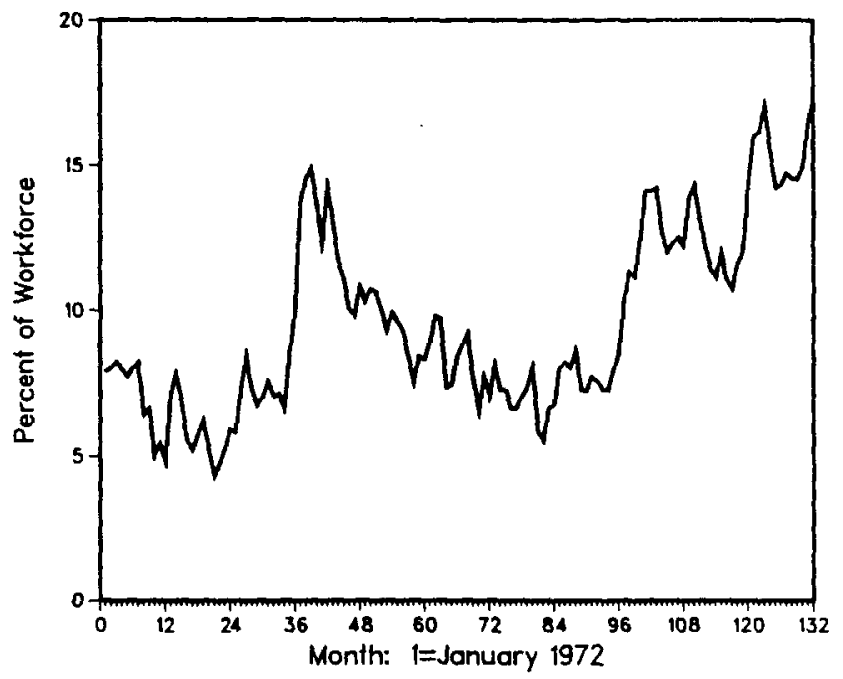

Fig. 2. Michigan unemployment rate.

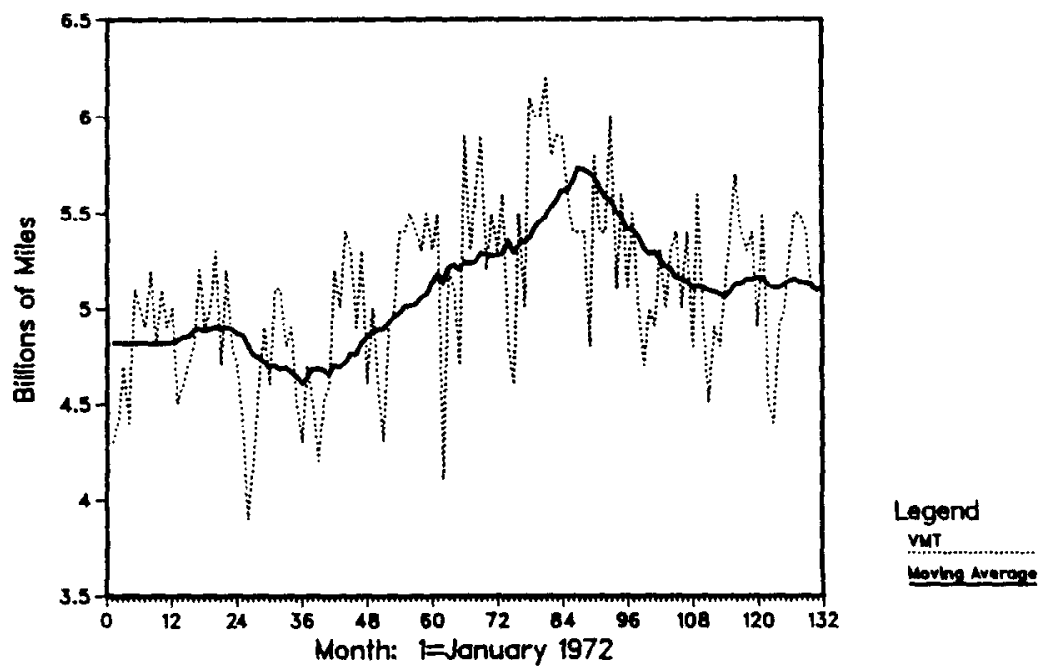

Fig. 3. Michigan vehicle miles traveled. 
The data analyses involved the development of parsimonious Auto-Regressive Integrated Moving Average (ARIMA) models for each variable. These models describe the stochastic autocorrelation structure of each series, and in effect filter out any variance in the variable that is predicable on the basis of the past history of that variable. There are a number of advantages of ARIMA modeling versus standard regression and common econometric techniques. Most importantly, ARIMA modeling procedures explicitly take into account all of the significant autocorrelations within each variable, and do not simply assume that the error terms are independent (as with ordinary least squares regression) or only characterized by first-order autoregression (as with many conventional econometric modeling techniques). The combination of dynamic regression models (i.e. transfer functions) with ARIMA models included an explicit examination of the lag structure of bivariate relationships under study, providing information on the time-ordered structure of the relationships, further increasing the degree of confidence in interpreting observed relationships in causal terms.

Each of the final models discussed below is the result of several repetitions of the specification, estimation, and diagnostic procedures originally developed by Box and Jenkins. The nonlinear backcasting algorithm found in BMDP2T [Dixon and others, 1983] was used for parameter estimation. All models were estimated iteratively until the relative change in the residual sum of squares was less than 0.00001 . Each of the models presented here meet all of the criteria for model adequacy suggested by Box and Jenkins. Accompanying the estimation results for each model is an analysis of residuals demonstrating the lack of significant remaining autocorrelation patterns. The revised Q-statistic developed by Ljung and Box [1976] was used as an overall test of the independence of the residuals.

Whether or not the reader is familiar with these methods, the important point to keep in mind when reviewing results of this study is the effect of using the Box-Jenkins methods on the allocation of explained variance. All variance in the dependent variable explainable (i.e. predicable) on the basis of the past history of the dependent variable is removed first. Remaining variance is then candidate for allocation to the effects of the independent variable. One implication of this approach is that any regular pattern over time in the dependent variable that is similar to the pattern of the independent variable over time is not considered as a possible causal effect between the two variables. Such intra-series regularities are filtered out first, and only random fluctuations in the independent variable from month to month are used to identify its potential effect on the dependent variable. This procedure has several advantages. First, effects of many exogenous variables that cause similar trends and cycles in both series are controlled. Second, independent error terms, required for unbiased estimation of the models, are obtained. However, it should also be recognized that these procedures are a conservative test of the causal connections between two time series. If similar trends and cycles in the two series are due to a causal connection between the series (rather than solely due to the common influence of the exogenous "seasonal" effect on both series), that causal connection will not be evident in a model controlling out those trends and cycles. Finally, regularities in time-series variables usually account for over half the variance in each series. Measurement and other random errors are a significantly larger portion of the variance of the residual series, reducing their sensitivity to effects of the independent variable. With these considerations in mind analysis results are discussed next.

\section{RESULTS}

A frequently used way to assess the relationship between two time-series variables is a visual comparison of the trends evident in the two series. Such a comparison of unemployment and traffic accidents in Michigan (Figs. 1 and 2) reveals an apparent inverse relationship between the two series. Increased unemployment in 1974 and 1975 is associated with decreased crash involvement; decreasing unemployment from 1976 to 1978 is associated with an upward trend in crashes; and finally, the high unemployment rates of 1980-1982 occur at a time of declining crash involvement. Although the sudden decrease in crash involvement in early 1974 is due to the fuel shortage and $55 \mathrm{mph}$ speed limit implemented at that time [O'Day and others, 1975], the multi-year trends in traffic accidents 
and unemployment since 1974 support the hypothesized inverse relationship between unemployment rate and frequency of traffic accidents.

As an initial step in measuring this relationship, cross correlations between unemployment and crash involvement were calculated. Because the effect of a monthly change in the rate of unemployment on crash involvement might not occur simultaneously, both the simple correlation and correlations at lags 1 through 9 were calculated. As seen in Table 1, a change in unemployment in a given month is inversely correlated with crash involvement in that month and crash involvement during the following several months. All the correlations are larger than twice their calculated standard errors. The correlation coefficients confirm the finding of an inverse relationship between rate of unemployment and number of drivers involved in accidents based on a visual analysis of the time-series plots.

The findings thus far confirm that there is an inverse association between unemployment rate and crash involvement. However, the more important question in this research is whether a change in unemployment rate causes a change in crash involvement. The correlations presented in Table 1 include the confounding effects of regular patterns within each time-series. For example, both unemployment rate and crash involvement are characterized by regular seasonal cycles; such cyclic patterns in the two series induce high cross correlations, even if there is no casual connection between the two variables. More generally. any autocorrelation patterns within each series will be confounded with the true cross correlations. To better identify the underlying relationship between unemployment and traffic accidents, independent of autocorrelation patterns in each variable, the time series modeling strategy developed by Box and Jenkins [1976] was used.

The first step was the development of an ARIMA model for the independent variable, unemployment. Using the iterative Box-Jenkins modeling procedures, the model shown in Table 2 was developed to account for the autocorrelation patterns in unemployment. As shown in Table 2, the model passed the diagnostic tests, producing a residual series that was white noise (i.e. independently distributed). The residuals from this ARIMA model, therefore, represent random fluctuations in the rate of unemployment that cannot be predicted from previous patterns in unemployment. Cross correlations of this residual series with the dependent variable, crash involvement, were then calculated to aid in the identification of a transfer function model for the relationship between unemployment and crash involvement. To maintain the structural relationship between unemployment and crash involvement, however, the crash time series was first filtered (i.e. transformed) using the equation shown in Table 2 representing the ARIMA model for unemployment. Cross correlations between the unemployment residuals and filtered crash involvement, therefore, represent relationships between random (unpredictable) month-to-month changes in unemployment and crash involvement (Table 3).

Table 1. Correlations of unemployment rate and crash involvement-raw data

SIMPLE CORRELATION OF UNEMPLOMENT AND CRASH INVOLVEMENT IS -0.62

CROSS CORRELATIONS OF UNEMPLOYMENT AND CRASH INVOLVEMENT AT LAG $K$

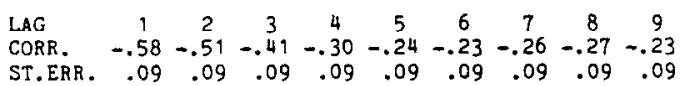

PLOT OF CROSS CORRELATIONS

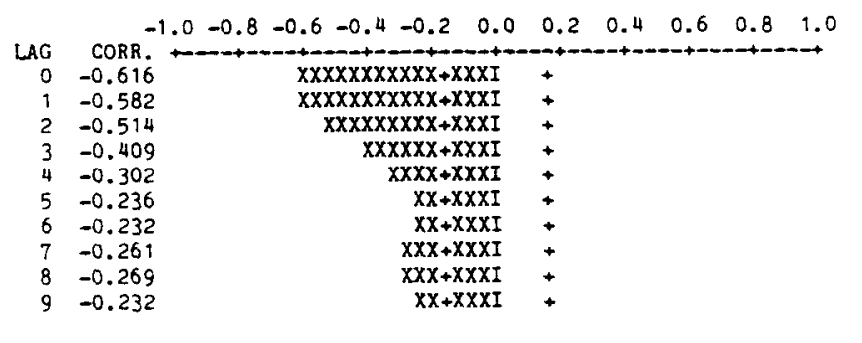


Table 2. ARIMA model for unemployment rate

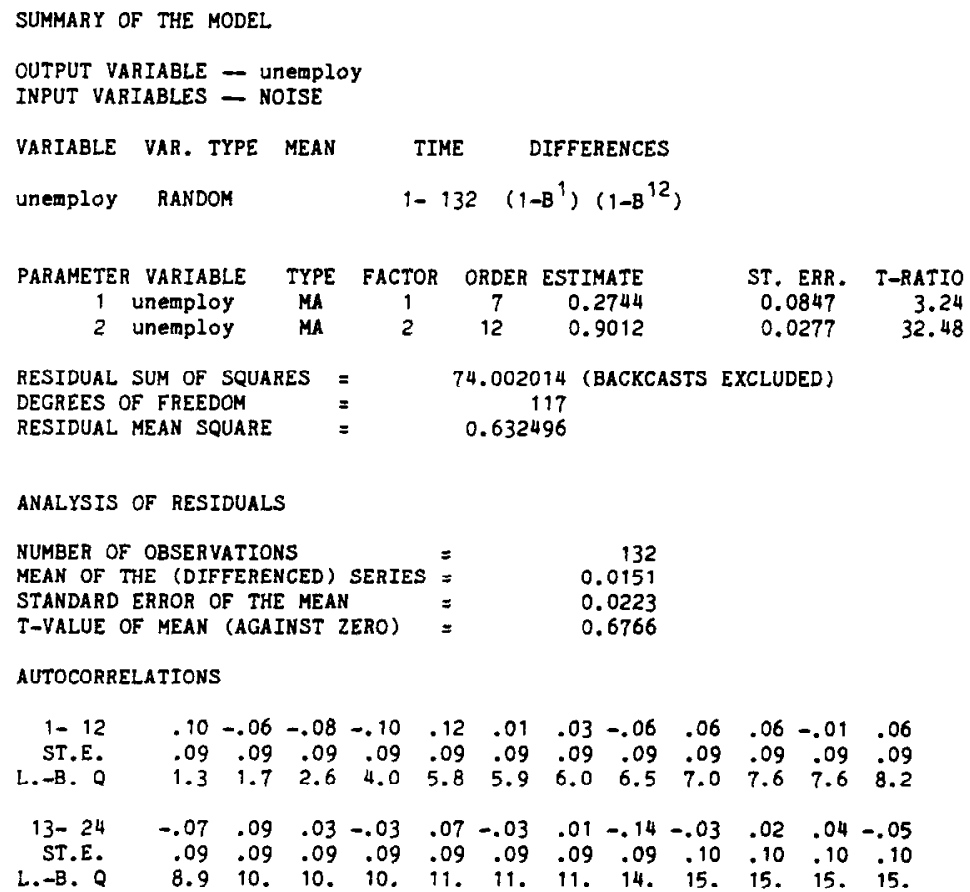

Table 3. Correlations of unemployment residuals and filtered crash involvement

SIMPLE CORRELATION OF UNEMFLOYMENT RESIDUALS AND FILTERED CRASHES IS -0.13 CROSS CORRELATIONS OF UNEMPLOYMENT RESIDUALS AND FILTEHED CRASHES AT LAG $K$

$\begin{array}{lccccccccc}\text { LAG } & 1 & 2 & 3 & 4 & 5 & 6 & 7 & 8 & 9 \\ \text { CORR. } & .14 & .05 & -.11 & 0.0 & .09 & -.07 & 0.0 & .09 & -.08 \\ \text { ST.EHR. } & .09 & .09 & .09 & .09 & .09 & .09 & .09 & .09 & .09\end{array}$

PLOT OF CROSS CORRELATIONS

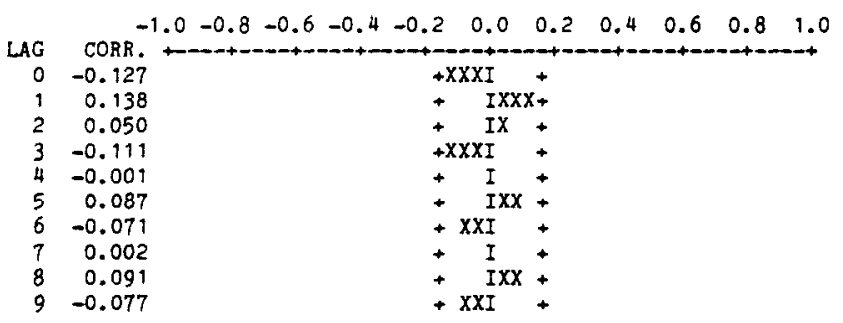

\section{TRANSFER FUNCTION WEIGHTS}

$$
\begin{array}{rr}
0 & -204.89325 \\
1 & 222.75938 \\
2 & 80.84454 \\
3 & -179.33237 \\
4 & -2.26902 \\
5 & 140.13553 \\
6 & -114.47792 \\
7 & 3.82125 \\
8 & 146.39337 \\
9 & -123.53151
\end{array}
$$


A comparison of Tables 1 and 3 indicate that most of the cross correlation between the ratc of unemployment and crash involvement in Table 1 is due to autocorrelation in the unemployment series. The coefficients in Table 3 are substantially smaller than those in Table 1, with none more than twice their standard errors. Since the link between unemployment and crash involvement was the focus of this research, and to ensure that a small effect was not missed, parameters for all correlations larger then their standard errors were included in an initial transfer function model. The estimation results indicated that the lag 3 parameter was not statistically significant, and it was therefore dropped from the model. The model was re-estimated; all remaining parameters were significant and the residuals were white noise. Results indicated that a one percentage-point increase in the unemployment rate is associated with a decrease of 316 drivers involved in injury crashes the month of the change in unemployment, and an increase of 237 drivers.involved in such crashes the month following the change in unemployment (Table 4). $\dagger$

A major anticipated intervening variable between the rate of unemployment and crash involvement is vehicle miles traveled. High unemployment rates may lead to fewer miles traveled, and the reduction in travel may cause reduced crash involvement. Trends in travel mileage (Fig. 3) were compared to trends in unemployment and crash involvement (Figs. 1 and 2). It appears that vehicle miles traveled is directly associated with crash involvement and inversely associated with the unemployment rate. However, as noted earlier, such a cursory visual examination of relationships between time series can be misleading. Therefore the Box-Jenkins procedures were also used to identify the potentially intervening influence of vehicle miles traveled in the relationship between unemployment and crash involvement.

Table 4. Transfer function model of unemployment on crash involvement

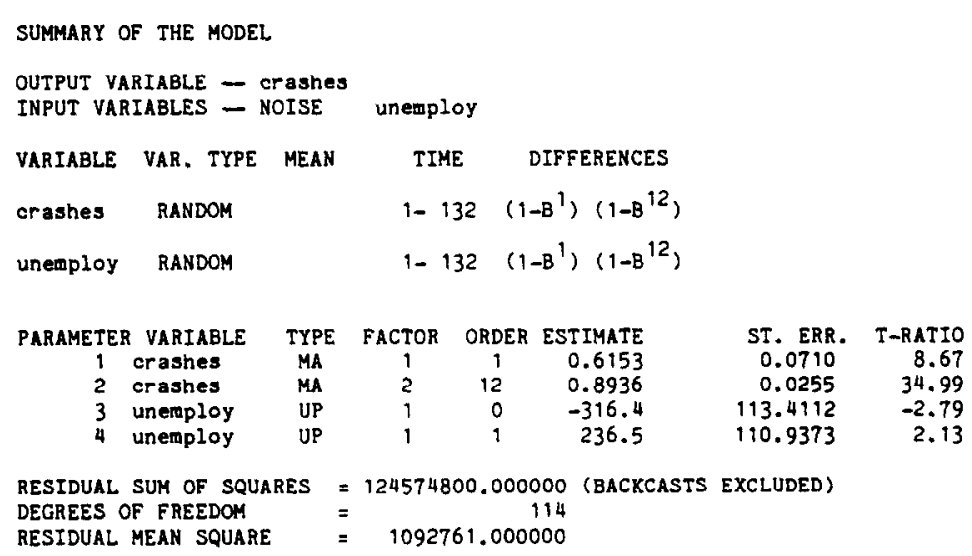

ANALYSIS OF RESIDUALS

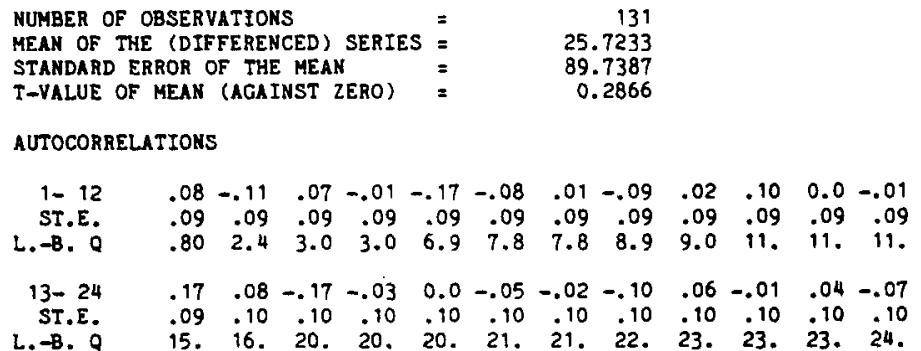

+Percentage-point changes are to be distinguished from percent changes. For example, if the unemployment rate is $10 \%$ and experiences a one percentage-point increase, the rate would then be $11 \%$, a $10 \%$ change in the rate. 
To isolate the random variation in vehicle miles traveled, an ARIMA model was developed to describe the autocorrelation structure of the series. The final model, shown in Table 5, reveals a significant seasonal cycle as well as second and third order autoregressive components in the series. To identify a transfer function representing the structural relationship between travel mileage and crash involvement, crash involvement was filtered with the ARIMA model for miles traveled, and the residual series for miles traveled and the filtered series for crash involvement were cross-correlated (Table 6). The cross correlations revealed significant positive coefficients for lags 1 and 2. Based on these results, a transfer function model incorporating the first and second-order relationships was estimated. Following the iterative Box-Jenkins model-building procedures, the final model in Table 7 was obtained. Estimation results indicated, as expected, a significant direct relationship between miles traveled and crash involvement. A one-billion increase in the number of miles traveled is associated with an increase in crash involvement of 949 drivers in the following month, and a further increase of 869 drivers in the second month after the change in travel mileage.

While a significant positive relationship between miles traveled and crashes was expected, the time lag for the effect to be fully evident was not anticipated. Reasons for the observed lag structure are not clear. Other unmeasured factors may be operating that are not yet well understood. One explanation focuses on errors in measurement. Estimated vehicle miles traveled is based partially on sales of motor fuel. Since a lag of one to two months may be expected between the time fuel is sold and the time it is fully used in travel, it is possible that the indicator of travel mileage used here is a leading indicator of actual miles traveled. If so, the estimated effects shown in Table 7 actually reflect a simultaneous rather than lagged relationship between travel mileage and crash involvement.

Up to this point we have found both a direct and an inverse relationship between unemployment and crash involvement, and a direct relationship between estimated miles traveled and crash involvement, in each case first controlling for the influence of all effects reflected in recurring patterns in each variable. If part of the effect of miles traveled on crash involvement is due to the causally antecedent effects of unemployment on travel,

Table 5. ARIMA model for vehicle miles traveled

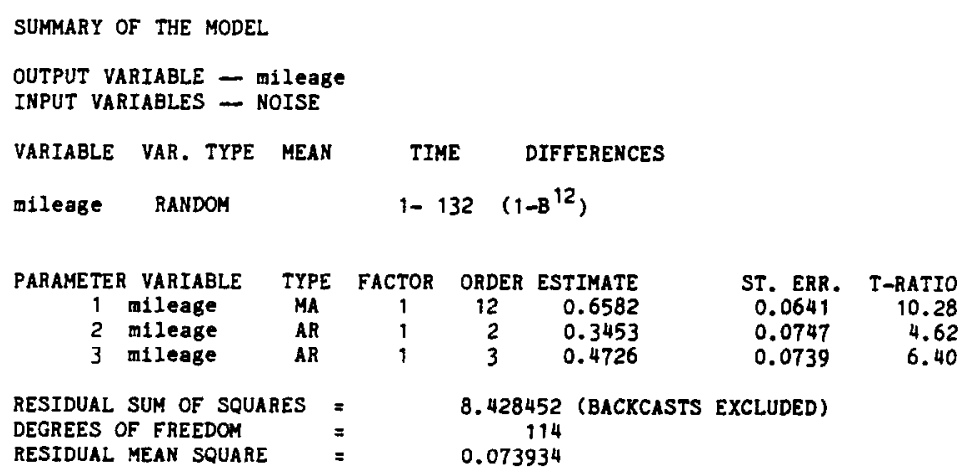

ANALYSIS OF RESIDUALS

NUMBER OF OBSERVATIOHS

MEAN OF THE (DIFFERENCED) SERIES $=0.132$

STANDARD ERROR OF THE MEAN = 0.0223

T-VALUE OF MEAN (AGAINST ZERO) $=10.0276$

AUTOCORRELATIONS

$\begin{array}{rrrrrrrrrrrrrr}1-12 & .10 & -.06 & -.08 & -.10 & .12 & .01 & .03 & -.06 & .06 & .06 & -.01 & .06 \\ \text { ST.E. } & .09 & .09 & .09 & .09 & .09 & .09 & .09 & .09 & .09 & .09 & .09 & .09 \\ \text { L. -B. Q } & 1.3 & 1.7 & 2.6 & 4.0 & 5.8 & 5.9 & 6.0 & 6.5 & 7.0 & 7.6 & 7.6 & 8.2 \\ & & & & & & & & & & & & \\ \text { 13- } 24 & -.07 & .09 & .03 & -.03 & .07 & -.03 & .01 & -.14 & -.03 & .02 & .04 & -.05 \\ \text { ST.E. } & .09 & .09 & .09 & .09 & .09 & .09 & .09 & .09 & .10 & .10 & .10 & .10 \\ \text { L.-B. Q } & 8.9 & 10 . & 10 . & 10 . & 11 . & 11 . & 11 . & 14 . & 15 . & 15 . & 15 . & 15 .\end{array}$


Table 6. Correlations of mileage residuals and filtered crash involvement

SIMPLE CORRELATION OF MILEAGE RESIDUALS AND FILTERED CRASH INVOLVEMENT IS 0.02 CROSS CORRELATIONS OF MILEAGE RESIDUALS AND FILTERED CRASH INVOLVEMENT aT LAG $\mathrm{k}$

$$
\begin{array}{lccccccccc}
\text { LAG } & 1 & 2 & 3 & 4 & 5 & 6 & 7 & 8 & 9 \\
\text { CORR. } & .24 & .20 & .05 & .04 & .09 & .11 & .14 & .04 & -.16 \\
\text { ST.ERR. } & .09 & .09 & .09 & .09 & .09 & .09 & .09 & .09 & .09
\end{array}
$$

PLOT OF CROSS CORRELATIONS

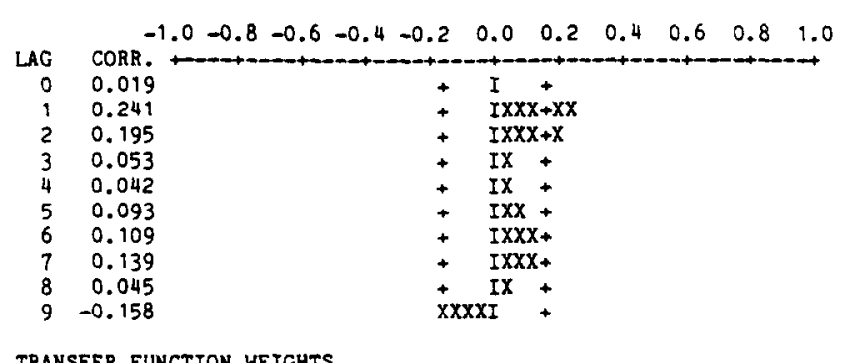

\section{TRANSFER FUNCTION WEIGHTS}

$$
\begin{array}{cr}
\text { LAG } & \\
0 & 89.00847 \\
1 & 1145.83643 \\
2 & 929.09521 \\
3 & 252.63689 \\
4 & 200.76961 \\
5 & 443.69922 \\
5 & 518.36646 \\
7 & 659.63208 \\
8 & 213.90540 \\
9 & -751.00073
\end{array}
$$

\begin{tabular}{|c|c|c|c|c|c|c|c|}
\hline \multicolumn{6}{|c|}{$\begin{array}{l}\text { OUTPUT VARIABLE - crashes } \\
\text { INPUT VARIABLES - NOISE mileage }\end{array}$} & & \\
\hline VARIABLE & VAR. TYPE & MEAN & TIM & & IFFERENCES & & \\
\hline crashes & RANDOM & & $1-1$ & $32<1-$ & $\left.-B^{1}\right)\left(1-B^{12}\right)$ & & \\
\hline mileage & RANDOM & & $1-1$ & $32(1-$ & $\left.-B^{1}\right)\left(1-B^{12}\right)$ & & \\
\hline $\begin{array}{c}\text { PARAMETER } \\
1 \\
2 \\
3 \\
4\end{array}$ & $\begin{array}{l}\text { VARIABLE } \\
\text { crashes } \\
\text { crashes } \\
\text { mileage } \\
\text { mileage }\end{array}$ & $\begin{array}{l}\text { TYPE } \\
\text { MA } \\
\text { MA } \\
\text { UP } \\
\text { UP }\end{array}$ & $\begin{array}{c}\text { FACTOR } \\
1 \\
2 \\
1 \\
1\end{array}$ & $\begin{array}{c}\text { ORDER } \\
1 \\
12 \\
1 \\
2\end{array}$ & $\begin{array}{r}\text { ESTIMATE } \\
0.7320 \\
0.8864 \\
948.6 \\
868.5\end{array}$ & $\begin{array}{c}\text { ST. ERR. } \\
0.0604 \\
0.0246 \\
340.8655 \\
332.5874\end{array}$ & $\begin{array}{r}T-R A T 10 \\
12.12 \\
36.09 \\
2.78 \\
2.61\end{array}$ \\
\hline
\end{tabular}

Table 7. Transfer function model of vehicle miles traveled on crash involvement

RESIDUAL SUM OF SQUARES $=115894416,000000$ (BACKCASTS EXCLUDED)

$\begin{array}{llr}\text { DEGREES OF FREEDOM } & =113 \\ \text { RESIDUAL MEAN SOUARE } & =1025614.250000\end{array}$

ANALYSIS OF RESIDUALS

NUMBER OF OBSERVATIONS

MEAN OF THE (DIFFERENCED) SERIES $=130$

$\begin{array}{lll}\text { T-VALUE OF MEAN (AGAINST ZERO) } & = & 90.5814 \\ & = & -0.0568\end{array}$

AUTOCORRELATIONS

$\begin{array}{rrrrrrrrrrrrr}\text { 1- 12 } & .12 & -.11 & .08 & -.04 & -.17 & -.10 & -.03 & -.02 & .09 & .13 & .04 & -.04 \\ \text { ST.E. } & .09 & .09 & .09 & .09 & .09 & .09 & .09 & .09 & .09 & .09 & 10 & .10 \\ \text { L.-B.Q } & 1.8 & 3.5 & 4.3 & 4.5 & 8.4 & 9.7 & 9.8 & 9.9 & 11 . & 14 . & 14 . & 14 . \\ 13-24 & .15 & .04 & -.23 & -.06 & 0.0 & -.02 & .04 & -.05 & .03 & -.01 & .01 & -.07 \\ \text { ST.E. } & .10 & .10 & .10 & .10 & .10 & .10 & .10 & .10 & .10 & .10 & .10 & .10 \\ \text { L.-B. Q } & 17 . & 17 . & 25 . & 26 . & 26 . & 26 . & 26 . & 27 . & 27 . & 27 . & 27 . & 28 .\end{array}$


unemployment should be related to travel mileage. A transfer function was developed to test this relationship. First, the residuals from the ARIMA model for rate of unemployment (Table 2) and residuals after filtering travel mileage by the same ARIMA model were cross-correlated, with the results shown in Table 8. The largest correlation, -0.157 , is at lag 2. Although not quite twice its standard error, a transfer function model was estimated to more precisely assess the significance of the unemployment-travel mileage relationship. Transfer function estimation results (Table 9) indicated no significant relationship between unemployment and miles traveled, consistent with the small correlation coefficient in Table 8.

Because unemployment and vehicle miles traveled are independent of each other, both were included in a combined transfer function model, to assess their independent effects on the dependent variable of interest, crash involvement. Application of the iterative model identification, estimation, and diagnosis strategy produced the final model shown in Table 10. Estimation results show a strong predictable seasonal cycle in crash involvement as well as a first-order moving average component in the differenced series. Significant independent effects on crash involvement of both unemployment and vehicle miles traveled are evident, consistent with the bivariate-equation estimation results discussed above. A one percentage-point increase in the rate of unemployment is associated with a concurrent decrease in crash involvement of 350 drivers, and an increase in crash involvement the following month of 298 drivers; averaging these two effects indicates the net estimated effect of a one percentage-point increase in unemployment is a monthly decrease of 52 drivers involved in injury crashes. Estimated vehicle miles traveled has an independent effect on crash involvement such that a one-billion-mile-per-month increase in travel results in 2007 more drivers involved in injury crashes over the subsequent two months.

\section{DISCUSSION}

The first hypothesis was that the rate of unemployment is inversely related to crash involvement due to the intervening influence of vehicle miles traveled. That is, increased unemployment would cause a decline in travel mileage, and reduced travel mileage would

Table 8. Correlations of unemployment residuals and filtered vehicle miles traveled

SIMPLE CORRELATION OF UNEMPLOYMENT RESIDUALS AND FILTERED MILEAGE IS -0.01

CROSS CORRELATIONS OF UNEMPLOYMENT RESIDUALS AND FILTERED MILEAGE AT LAG $K$

$$
\begin{array}{lccccccccc}
\text { LAG } & 1 & 2 & 3 & 4 & 5 & 6 & 7 & 8 & 9 \\
\text { CORR. } & .13 & -.16 & .06 & -.04 & .05 & -.08 & .06 & .04 & -.10 \\
\text { ST.ERR. } & .09 & .09 & .09 & .09 & .09 & .09 & .09 & .09 & .09
\end{array}
$$

PLOT OF CROSS CORRELATIONS

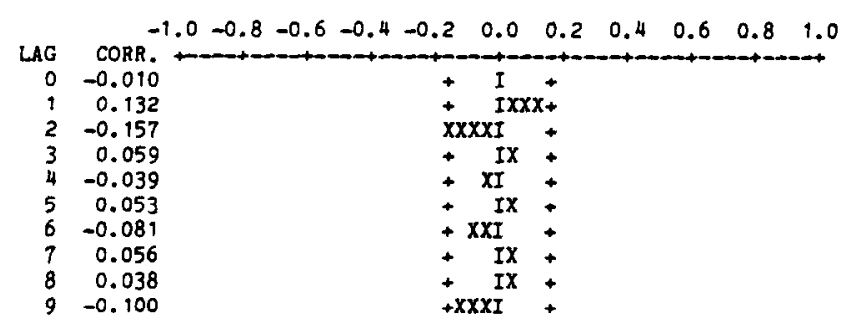

TRANSFER FUNCTION WEIGHTS

$$
\begin{array}{cr}
\text { LAG } & \\
0 & -0.00488 \\
1 & 0.06743 \\
2 & -0.07995 \\
3 & 0.03028 \\
4 & -0.01987 \\
5 & 0.02708 \\
6 & -0.04141 \\
7 & 0.02830 \\
8 & 0.01954 \\
9 & -0.05092
\end{array}
$$


Table 9. Transfer function model of unemployment on vehicle miles traveled

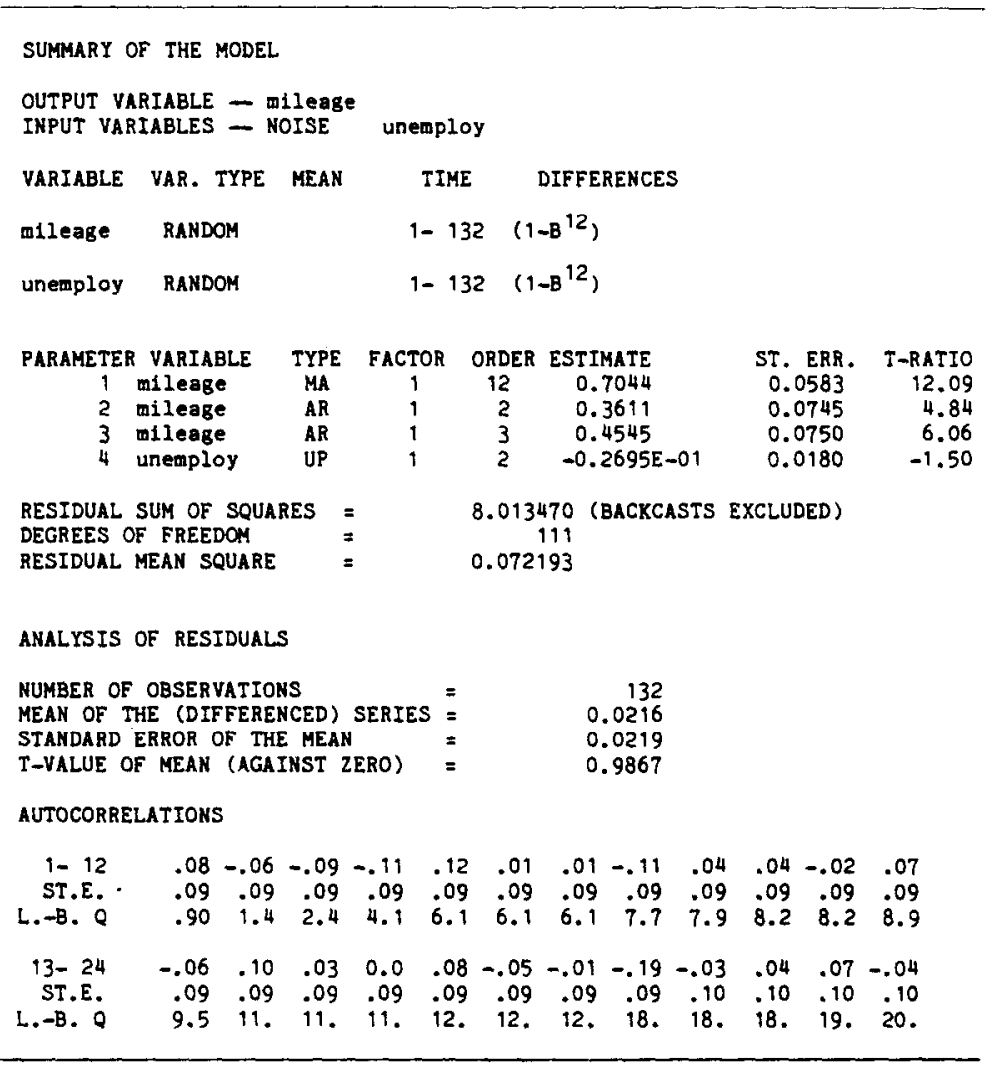

lead to fewer crash-involved drivers. This hypothesis was not supported by the data analyzed. Although travel mileage is related to the number of crashes, changes in the unemployment rate are not significantly related to the number of miles traveled (after controlling for intra-series autocorrelation patterns). The second hypothesis was that the unemployment rate is directly related to the level of mental stress experienced by the population, and stress is directly related to subsequent involvement in traffic crashes. Although stress as an intervening variable was not measured in this study, finding a significant positive relationship between changes in the rate of unemployment and the number of crash-involved drivers one month later supported this hypothesis. First, consider the component of the effects of increased unemployment represented by those who lose their jobs. Increased stress associated with job loss is not necessarily concentrated in the month in which one is laid off. The first few weeks of joblessness may be perceived as a break from routine, and an opportunity to catch up on a backlog of personal tasks. Stress is likely to increase a month later for both those who find new employment, and those who remain unemployed. Those in the former group experience the stress of adapting to a new work environment. Those in the second group begin to realize the lack of opportunity to return to a job as desirable as the one they had had. Both segments of the unemployed population, then, experience more stress in the month following layoff than in the month in which the layoff takes effect, consistent with the significant increase in crash involvement one month after an increase in unemployment.

The second component in the positive lag-one relationship between unemployment and crash involvement is the effect of a change in the rate of unemployment on the great majority of the population that does not lose their job. The psychological effects of high rates of unemployment on this part of the population presumably do not occur until people become aware of changes in the unemployment rate. The general population becomes aware of an increase in unemployment in the month following the actual change, when the previous month's unemployment statistics are widely disseminated through the mass media. This 
Table 10. Transfer function model of unemployment and mileage on crash involvement

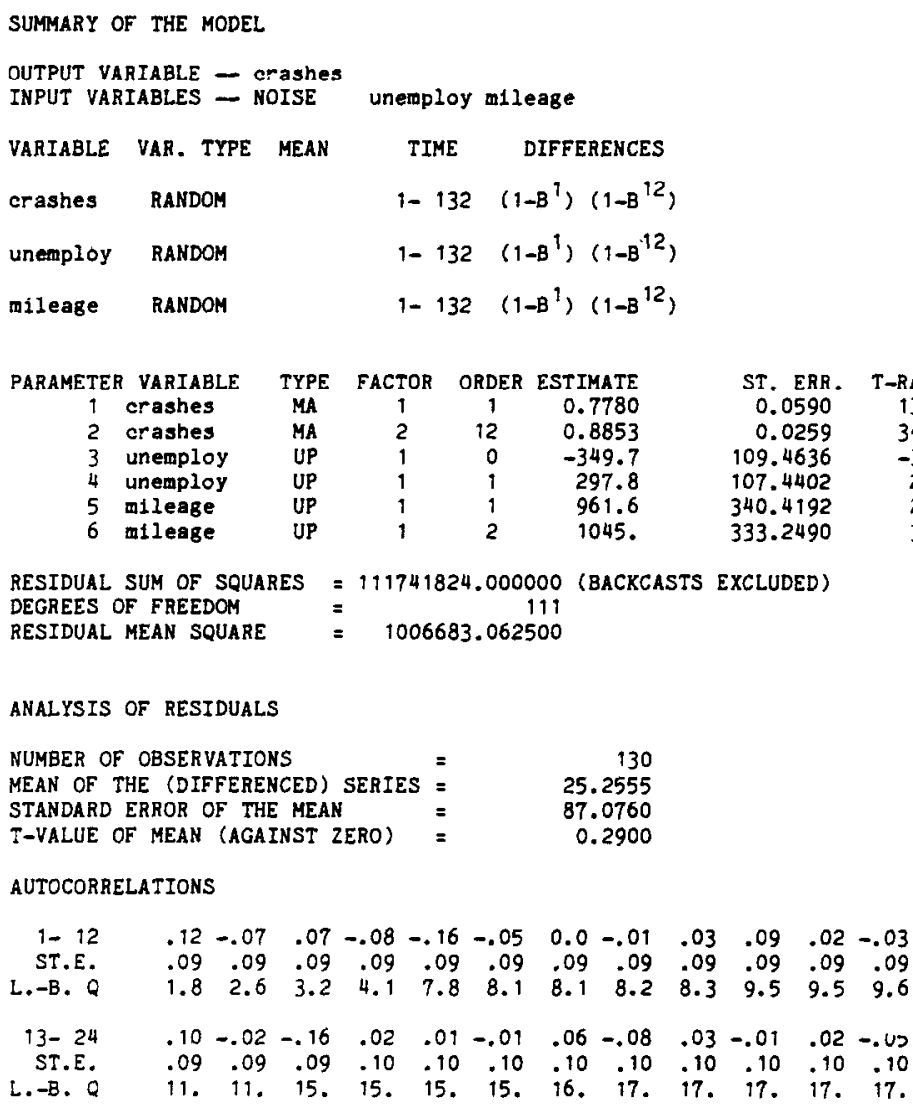

one-month lag in awareness is consistent with the observed one-month lag in the significant positive relationship between unemployment and crash involvement.

A third major finding of this study is a significant simultaneous inverse relationship between unemployment rate and frequency of traffic crashes. This relationship also has multiple explanations. As noted above, the newly unemployed may experience less stress at the time of layoff than before or after losing their job. These relatively low stress levels may lead to reduced risk of crash involvement. Second, and perhaps more plausibly, there may be a substantial change in driving patterns at the time of layoff. The change in pattern may involve increased driving for running errands and seeking work during the relatively safe weekday daytime hours, and decreased recreational driving during the more-dangerous weekend nighttime hours. Although no change in total vehicle miles traveled is associated with unemployment, such changes in typical driving patterns may significantly reduce the risk of involvement in traffic crashes.

There are a number of possible dimensions of the link between unemployment and crash involvement that have not been considered in this initial study. For example, impairment caused by consumption of beverage alcohol plays a role in a significant proportion of injury crashes. As a result, effects of economic conditions on drinking and driving-after-drinking patterns may mediate the unemployment-crash involvement relationship. The aggregate relationship between unemployment and crash involvement is most likely the result of a combination of several effects. Other possible effects might include more careful driving during economic recessions due to the desire to avoid expenses of repair or replacement of one's automobile. High unemployment typically reduces new car sales, reducing the amount of driving in new, unfamiliar vehicles, and therefore reducing crash risk. On the other hand, reduced new car sales leads to a higher proportion of older vehicles on the road. Since older vehicles are more likely to be involved in crashes, the net effect may be increased crash rates. 
The present study does not resolve the debate concerning multiple theoretical causal links between economic conditions and traffic crashes. However, policy makers and program managers may be more interested in the magnitude of the effects rather than their precise theoretical specification. The relationships between unemployment and crash involvement observed here are statistically significant at any reasonable probability level. The simultaneous inverse relationship represents a $2.5 \%$ decline in crash involvement for each one percentage-point increase in unemployment (based on a monthly average of 13,955 Michigan drivers involved in injury crashes over the 1972 through 1982 period). The positive lag-one relationship represents a $2.1 \%$ increase in crash involvement for each one percentage-point increase in unemployment. If the inverse simultaneous and positive lagone relationships between unemployment and crash involvement are summed, the net effect of a one percentage-point increase in the unemployment rate is a monthly decline of 52 drivers involved in injury traffic accidents, representing a four-tenths of one percent decline in injury crash involvement. Consistent with the small magnitude of the net unemployment effect, the rate of unemployment explains a relatively small part of the total variation in crash involvement over time. The time series model incorporating the ARIMA component and the transfer function for vehicle miles traveled explained $75.6 \%$ of the variance in crash involvement. The addition of the unemployment parameters to the model increased the explained variance to $76.0 \% \dagger$ Given the multitude of factors that affect the aggregate frequency of crash involvement, a much larger increase in explained variance cannot be expected.

Implications of these findings for policy makers are as follows. First, increased unemployment in recent years has lead to a reduction in the number of drivers involved in crashes. However, economic conditions, as reflected in the unemployment rate, account for only a small part of reduced crash involvement in the early 1980s. The recent economic recession cannot be used to "explain away" declines in crash involvement during this period. Most of the recent decline in crash involvement is apparently due to other factors. Controlled studies focused on the State of Michigan have found that an increase in legal minimum drinking age (effective December 1978) and a mandatory child restraint law (effective April 1982) have been effective in reducing crash injuries [Wagenaar, 1983, 1984]. Strengthened enforcement of drinking-driving laws, enhanced public information and education programs, and other renewed traffic safety efforts may be contributing to the decline in crash involvement, although controlled studies of these activities have not yet been conducted.

Finally, a couple of methodological issues should be noted. The time series modelling procedures employed here are conservative in the sense of being less likely to find what appear to be significant statistical relationships than conventional correlation and regression techniques. However, the Box-Jenkins methods have two very important advantages, and their use should therefore be encouraged in research on predictors of crash involvement. First, the underlying relationships between changes over time in two variables are identified, not corrupted by the spurious cross correlations produced by intra-series regularities. Second, controls for autocorrelations in the dependent variable allow unbiased estimates of standard errors for the parameters to be obtained, providing a more accurate assessment of the statistical significance of parameter estimates.

Additional research is clearly needed to clarify the role of numerous factors that mediate the effects of economic conditions on crash involvement. Analyses reported here should be replicated with data from other jurisdictions. Replication within the same jurisdiction using alternate dependent variables, such as suicide rate, may improve our understanding of the relationship between economic conditions, stess, and behavior. The multiple dimensions of economic change should be measured, and their independent effects on traffic safety assessed. For example, the single indicator used in this study, the rate of unemployment, is directly a result of two factors, the number of people without work

†The small increase in explained variance attributable to the independent variable is partially a result of the analysis methods. As indicated earlier, most of the variance in the dependent variable is attributed to identifiable regularities in the dependent variable. Therefore, the independent variable explained a larger proportion of the remaining variance than a comparison of the total $\mathrm{R}$-squares would indicate. 
seeking employment and the number of people in the workforce. Changes in the size of the workforce may influence the rate of unemployment, with no change in the total number of people employed. The investigation reported here is continuing along these lines.

Given that motor vehicle occupant injury is one of the most serious public health problems, and that increased attention both among policy makers and the public is being given to the crash problem, further epidemiological research on factors influencing crash involvement is to be encouraged.

\section{REFERENCES}

Appel C-P., Blomkvist A-C., Persson L-O. and Sjoberg L., Mood and achievement in a difficult driving task. Ergonomics 23(7), 605-612, 1980.

Box G. E. P. and Jenkins G. M. Time Series Analysis: Forecasting and Control. Revised Edition. Holden-Day, San Francisco, 1976.

Burgess E. The growth of the city: an introduction to a research project. In The City (Edited by R. Park and E. Burgess), pp. 47-62. University of Chicago Press, Chicago, 1925.

Catalano R. and Dooley D., The behavioral costs of economic instability. Policy Studies J. 10(2), 338-349, 1981.

Catalano R. and Dooley D., Health effects of economic instability: A test of economic stress hypothesis $J$. Health and Social Behavior 24, 46-60, 1983.

Cerrelli E. C. The 1982 Traffic Fatalities Early Assessment. National Highway Traffic Safety Administration, Washington, D.C., 1983

Cottrell F., Death by dieselization: A case study in the reaction to technological change. Amer. Sociological Rev. 16, 358-365, 1951.

Dixon W. J., Brown M. B., Engelman L., et al., BMDP Statistical Software: 1983 Printing with Additions. University of California Press, Berkeley, California, 1983.

Dohrenwend B. P., Sociocultural and socio-psychological factors in the genesis of mental disorders. J. Health and Social Behavior 16, 365-392, 1975.

Dooley D. and Catalano R., Economic change as a cause of behavioral disorder. Psychological Bulletin 87, $450-468,1980$.

Durkheim E., Suicide: A Study in Sociology. Free Press, Glencoe, Illinois, 1951.

Eyer J. Prosperity as a cause of death. Int. J. Health Services 7(1), 125-150, 1977.

Highway and Vehicle Safety Report. Many states to consider drunk driving, child restraint laws. 9(10), 2, 7 February 1983.

Holt P. L., Stressful life events preceding road traffic accidents. Injury 13, 111-115, 1982.

Insurance Institute for Highway Safety, Decline in auto crash fatalities tied to economy. Highway Loss Reduction Status Report, 18(9), 1-3, 1983.

Kasl S. and Cobb S., Some mental health consequences of plant closing and job loss. In Mental Health and the Economy. (Edited by L. Ferman and J. Gordus), Upjohn Institute, Kalamazoo, Michigan, 1979.

Liem R. and Liem J., Social class and mental illness reconsidered: The role of economic stress and social support. J. Health and Social Behavior, 19, 139-156, 1978.

Ljung G. and Box G. E. P., Studies in the Modeling of Discrete Time Series 3: A Modification of the Overall Chi-square Test of Lack of Fit in Time Series Model, Tech. Rep. 477. University of Wisconsin, Department of Statistics, Madison, 1976.

Mizruchi E. H., Success and Opportunity: A Study in Anomie, pp. 106-108. The Free Press, Glencoe, Illinois, 1964.

National Safety Council. Accident Facts. Chicago, 1982.

O'Day J., Minahan D. J. and Golomb D., The Effects of the Energy Crisis and 55 mph Speed Limit in Michigan. The University of Michigan Highway Safety Research Institute, Ann Arbor, 1975.

Ogburn W., Social Change. Viking Press, New York, 1936.

Physicians for Automotive Safety, PAS News. Spring, 1983.

Selzer M. L. and Vinokur A., Role of life events in accident causation. Mental Health and Society, 2, 36-54, 1975.

Verway D. I. (ed.), Michigan Statistical Abstract, 17th Edition. School of Business Administration, Wayne State University, Detroit, 1983.

Wegenaar A. C., Alcohol, Young Drivers, and Traffic Accidents: Effects of Minimum-Age Laws. D. C. Heath, Lexington, Massachusetts, 1983.

Wagenaar A. C., Restraint Usage Among Crash-involved Motor Vehicle Occupants. The University of Michigan Transportation Research Institute, Ann Arbor, 1984. 